\title{
The Description of Illness Representation Occurred in Hypertension and Diabetes Patients in Makassar City
}

\author{
Annisa Yurna Megarezky ${ }^{1 *}$, Grestin Sandy ${ }^{2}$, Mayenrisari Arifin ${ }^{3}$ \\ ${ }^{1}$ Hasanuddin University Makassar, Indonesia \\ ${ }^{2}$ Hasanuddin University Makassar, Indonesia \\ ${ }^{3}$ Hasanuddin University Makassar, Indonesia \\ *Corresponding author. Email: annisa.yurna@yahoo.com /phone: (+62)82114412369
}

\begin{abstract}
Non-infectious diseases (i.e., stroke, hypertension, diabetes mellitus, tumor, and cardiovascular disease) are Indonesia's main causes of death. Diabetes and hypertension are diseases that could be treated quickly. However, many patients choose to delay the treatment, and some decide not to treat their diseases. One of the essential factors that persuade patients in the treatment or medication is the representation or understanding regarding their diseases reviewed from five dimensions: identity, causes, timeline, consequences, and controllability. This research aims to explain the illness representation on hypertension and diabetes patients in Makassar city with respondents as many as 145 patients (73 hypertension patients and 73 diabetes patients). The research data was collected through IPQ (Illness Perception Questionnaire) and open interview. This research showed that hypertension patients and diabetes patients dominantly remain on the category of quite capable of representing their diseases if reviewed from five dimensions illness representation. Patients often did not realize the early symptoms of the diseases, the causes of the diseases, the duration of their diseases, the consequences, and how to cope/overcome with the disease, thereby on several patients, they started the treatment when the condition was chronic. This is happening because diabetes and hypertension are silent killers, so patients need to have a good representation regarding their condition.
\end{abstract}

Keywords: Illness representation, hypertension, diabetes, diabetic, health psychology, clinical psychology, health

\section{INTRODUCTION}

Health is one of the most important things for every individual. However, individuals will experience illness at some point in their life [1]. Individuals who are sick will experience an illness experience. Chronic and acute diseases often found in Indonesia are Diabetes Mellitus and Hypertension. The results of the 1995-2001 Household Health Survey and Riskesdas 2007 shown that noncommunicable diseases (such as stroke, hypertension, diabetes mellitus, tumors, and heart disease) are the leading causes of death in Indonesia [2]. The prevalence of people with diabetes mellitus in South Sulawesi in 2013 was $1.6 \%$ and then increased to $1.8 \%$ in 2018. In addition, based on [3], the prevalence of hypertension sufferers in South Sulawesi is $8 \%$.

Individuals are active patients in dealing with problems (in this case, illness). It can be seen from their efforts to interpret symptoms and find ways to overcome them [4]. The existence of beliefs regarding the illness affects individuals choosing the first type of treatment when symptoms are felt. Individuals adapting to their condition or illness are influenced by several factors, such as the representation of the illness (illness representation), psycho-emotional impact experienced, specific clinical characteristics and evolution, history of the appearance of the same disease in the family, and social context [5].

The individual's cognitive ability in interpreting the symptoms he feels can lead the individual to understand the illness he is suffering from and seek treatment assistance. However, in reality, patients with diabetes mellitus and hypertension often cannot understand the symptoms they feel, which affects them in handling the disease. That is supported by interviews conducted with patients with diabetes mellitus. The patient admitted that he had long felt 
the symptoms of diabetes, but he did not know that these symptoms were symptoms of diabetes. After the symptoms did not subside, the patient decided to see a doctor and just realized that he had been experiencing symptoms of diabetes mellitus. The patient then takes herbal medicines, such as Putri Malu leaves and dragon fruit, and the doctor's prescription.

In addition, the results of interviews with hypertensive patients also showed that the symptoms experienced by patients were not known beforehand. The patient admitted that he began to know that he had hypertension after checking his blood pressure. Patients feel surprised because they think these symptoms do not indicate a particular disease. The patient has consumed doctor and herbal medicine (such as garlic boiled water). Therefore, researchers are interested in examining illness representation in hypertensive and diabetic patients.

\subsection{Illness Representation}

Leventhal et al. (1980) defined the term illness representation, which is defined as an individual's belief regarding the illness they are experiencing [1]. These cognitions describe an individual's schema for coping with and understanding their illness. Thus, Illness representation is often referred to as an individual's cognition of disease [6]. Leventhal et al. (1998) also suggested that when individuals begin to feel symptoms, it will start with the symptom recognition or assessment stage (the period when they start to feel symptoms until they determine that the symptoms are indicators of disease). Then, the stage of the individual in a sick condition (the period when the individual determines that he is sick and asks for expert help). Finally, the utilization stage is the period from asking for help to getting expert treatment. The critical point is that the level of representation determines individual compliance [1]. It can be concluded that illness representation is all images, beliefs, expectations, and understandings regarding the condition of the illness they are experiencing.

\subsection{Illness Representation Dimensions}

Leventhal et al (1980) suggested four dimensions of illness representation, namely: identity (identity/label), timeline (duration/period of time), cause (cause), and consequences (consequences) [1]. Furthermore, Lau and Hartman (1983) added a fifth dimension, namely, cure or controllability (the extent to which the disease can be overcome or treated). Thus, illness representation is known to have five dimensions [7]. Laventhal's subsequent studies and self-regulatory models also use these five dimensions:

\subsubsection{Identity}

This dimension includes the patient's beliefs about the possible label of a condition/somatic symptom that he feels [8]. Singh (2011) argues that this dimension refers to the labels used by individuals to describe their illness. When individuals feel specific symptoms, they begin to look for labels for their symptoms [9]. For example, when an individual feels his nose is stuffy, he will think he has influenza [6].

\subsubsection{Timeline}

This dimension includes individual beliefs (beliefs) regarding the duration of the illness, the length of time required for treatment, and the length of time it takes for the worst possible disease to occur when treatment is not carried out [10]. In addition, Singh (2011) suggests that this dimension refers to the individual's perception of the disease, whether the illness is acute, chronic, or cyclical [9]. For example, individuals believe that their flu will only last two days [6].

\subsubsection{Causes}

This dimension includes the causes of disease, such as external agents (bacteria, viruses, stress, and other external agents), internal susceptibility (gene factors), and behavioral causes of disease (such as collisions that can cause breast cancer) [10]. Ogden (2012) added that the causes of illness could be biological (such as a virus or injury) or psychosocial (such as stress or health-related behaviors). For example, individuals think their flu is caused by a virus [6].

\subsubsection{Consequences}

This dimension includes the causes of disease, such as external agents (bacteria, viruses, stress, and other external agents), internal susceptibility (gene factors), and behavioral causes of disease (such as collisions that can cause breast cancer) [10]. Ogden (2012) added that the causes of illness could be biological (such as a virus or injury) or psychosocial (such as stress or health-related behaviors). For example, individuals think their flu is caused by a virus [6].

\subsubsection{Controllability}

This dimension relates to the anticipatory response and the response given to treatment and further action [10]. Ogden (2012) also argues that patients represent disease when they believe that the disease can be treated and managed and the extent to 
which the outcome of their illness can be controlled, either by themselves or by other skilled people. For example, the individual believes that when he rests, the flu will go away [6].

\subsection{Influencing Factors of Illness Representation}

Representation is closely related to individual reality, seen from three ways: (1) the dimension of the physical world, including the somatic experience of the body that determines the basis of an experience [11]; (2) common-sense, individual representations produce goals or targets for adaptive actions and are validated or not by internal and external feedback influenced by actions leading to those goals; last, (3) the accumulation of experiences of others, this is in the form of social and cultural information, which plays a vital role in forming individual representations and choosing appropriate coping procedures [11]. Thus, two factors can be grouped that affect illness representation, namely:

\subsubsection{Individual Personal Context}

An individual's medical history can produce experiences that significantly impact the individual's representation of the somatic stimuli that the individual will experience in the future and impact the formation of emotional responses and coping procedures [12]. When the stimulus comes from within the individual, it will produce an individual representation based on the similarity of the condition to the schema structure experienced.

\subsubsection{Socio-cultural Context}

There are several cultural influences and the construction of illness representations. First, culture determines the symptoms that can be conveyed related to the illness. If somatic symptoms are more acceptable than psychological symptoms in a culture, the former will be included in the representation of the disease, and the latter will be excluded. Second, the symptoms or symptoms determine the individual's expectations regarding treatment. The cultural context forms the framework for individual illness representation. Leventhal et al. in Baum et al. (2001) also revealed that the social factors that shape the schema about illness are not only from the family but how individuals see other individuals around them who are sick, the mass media reporting on illness and death, discussions regarding causes and disease consequences. That impacts individual schemas formed by the somatic experiences they experience [10].

\subsection{Illness Representation on Self- Regulatory Model}

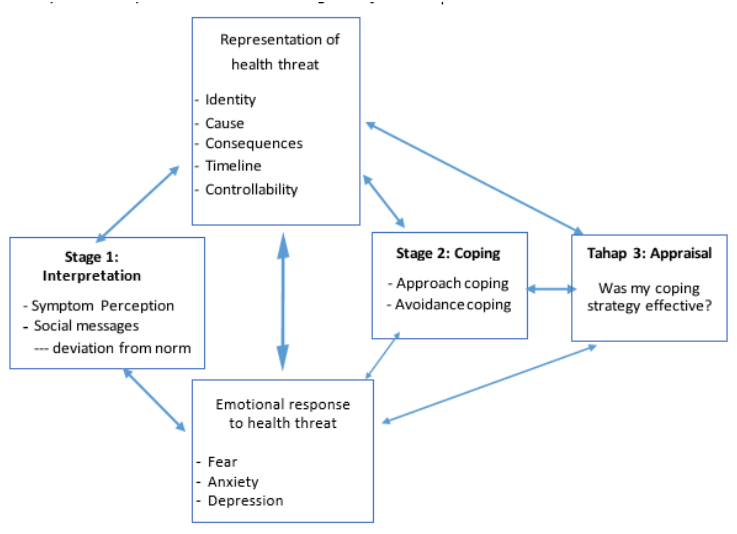

Figure 1 Self-Regulatory Model (Ogden, 2012)

There are three stages in Leventhal's SelfRegulatory. These three stages can explain the dynamics of the individual in overcoming the symptoms he feels. Ogden [6] illustrates the three stages referring to Leventhal, as follows:

\subsubsection{Stage 1: Interpretation}

Individuals are faced with problems related to possible disease in two ways, namely symptom perception and social messages. When individuals receive information about the possible disease, individuals will be motivated to let go of the unpleasant condition. A problem will be given meaning by accessing illness cognition (disease representation), constructed with illness representation dimensions. The representation of this disease will then direct the individual to develop coping strategies. However, not only cognitive representations but also affect emotional responses.

\subsubsection{Stage 2: Coping}

Individuals can choose the type of coping. Two forms of coping individuals can select approach coping and avoidance coping. Coping approaches, such as: taking medication, seeing a doctor, resting, talking to friends about the emotions they feel. Meanwhile, avoidance coping such as: rejecting or hoping for the best.

\subsubsection{Stage 3: Appraisal}

At this stage, the individual assesses the effectiveness of the coping that has been chosen. In addition, individuals also begin to determine whether to continue their chosen coping strategy or choose other alternatives. 


\section{METHOD}

This research is quantitative research with the type of non-experimental research. The population of this study is residents of Makassar City, but with the total population, the researchers set the respondent criteria: Makassar City residents who have been diagnosed with hypertension and diabetes. Thus, the study was conducted on 145 respondents, consisting of 72 hypertension patients and 73 diabetes mellitus patients with accidental sampling technique. Respondents were obtained from several hospitals, health centers, and relatives who met the criteria of research respondents.

The data collection technique carried out in this study consisted of an interview process as initial data as well as complementary data and with the Illness Perception Questionnaire (IPQ) measuring instrument, which was developed by Weinman et al. (1996) which has been adapted into Indonesian [13]. The IPQ instrument is a questionnaire that aims to see the respondent's illness representation, containing questions that reflect the dimensions of the illness representation, such as identity, timeline, cause, consequence, and controllability. The validity of the IPQ measuring instrument was carried out to 10 experts (doctors and psychologists who understand the research variables and have treated hypertension and diabetes patients) who assessed each item on the IPQ. The reliability of the IPQ measuring instrument is based on the Cronbach's Alpha value of 0.734 , which is included in the reliable category. The hypothesis in this study is H0: There is no difference between the illness representation of hypertension and diabetes patients in Makassar City. Thus, the Mann-Whitney hypothesis test was also carried out and descriptive analysis. This research was declared to have received ethical approval by the Health Research Ethics Committee of the Medical Faculty Hasanuddin University, number 648/UN4.6.4.5.31/PP36/2019.

\section{RESULT}

\subsection{Sociodemographic Participants}

Demographic data of respondents showed that the majority of respondents with diabetes and hypertension were male, as many as $56.16 \%$ (41 people) for male diabetic respondents and $51.39 \%$ (37 people) for hypertension respondents. Furthermore, the age range of the respondents was dominated by respondents aged 51-60 years in both hypertension and diabetes patients. For the type of treatment carried out, most hypertensive and diabetic patients chose medical treatment, as many as 28 diabetic patients $(38.36 \%)$ and 27 hypertensive patients $(37.50 \%)$. The duration of the illness suffered by hypertensive and diabetic patients showed that most of the duration was 1-5 years, 38 diabetic patients $(52.05 \%)$ and 51 hypertensive patients $(70.83 \%)$. More details can be seen in table 1.

Table 1. Sociodemographic participants

\begin{tabular}{|c|c|c|}
\hline \multirow[b]{2}{*}{ Variables } & \multicolumn{2}{|c|}{ Characteristics } \\
\hline & $\begin{array}{c}\text { Diabetes Melitus } \\
\text { N }(\%)\end{array}$ & $\begin{array}{l}\text { Hypertension } \\
\text { N }(\%)\end{array}$ \\
\hline \multirow{2}{*}{ Sex of participants } & Male $=41(56,16 \%)$ & Male $=37(51,39 \%)$ \\
\hline & Female $=32(43,84 \%)$ & Female $=35(48,61 \%)$ \\
\hline \multirow{5}{*}{ Age } & $<20-40=7(9,59 \%)$ & $<20-40=14(19,44 \%)$ \\
\hline & $41-50=16(21,92 \%)$ & $41-50=14(19,44 \%)$ \\
\hline & $51-60=25(34,25 \%)$ & $51-60=26(36,11 \%)$ \\
\hline & $61-70=17(23,29 \%)$ & $61-70=7(9,72 \%)$ \\
\hline & $>70=8(10,96 \%)$ & $>70=11(15,28 \%)$ \\
\hline \multirow{5}{*}{$\begin{array}{l}\text { Treatment chosen when } \\
\text { symptoms are felt }\end{array}$} & $\begin{array}{l}\text { Alternatives }(\text { herbs, traditional })=9(12,33 \%) \\
\text { Medical }=28(38,36 \%)\end{array}$ & $\begin{array}{l}\text { Alternatives (herbs, traditional) }=7 \\
(9,72 \%)\end{array}$ \\
\hline & Buy medicine without a prescription $=18$ & Medical = $27(37,50 \%)$ \\
\hline & $(24,66 \%)$ & Buy medicine without a prescription $=22$ \\
\hline & Others $=13(17,81 \%)$ & $(30,56 \%)$ \\
\hline & No Treatment $=5(6,85 \%)$ & $\begin{array}{l}\text { Others }=6(8,33 \%) \\
\text { No Treatment }=10(13,89 \%)\end{array}$ \\
\hline \multirow{4}{*}{ Duration of Illness } & $1-5$ years $=38(52,05 \%)$ & $1-5$ years $=51(70,83 \%)$ \\
\hline & $6-10$ years $=18(24,66 \%)$ & $6-10$ years $=15(20,83 \%)$ \\
\hline & $11-20$ years $=13(17,81 \%)$ & $11-20$ years $=6(8,33 \%)$ \\
\hline & $>20$ years $=4(5,48 \%)$ & $>20$ years $=0$ \\
\hline
\end{tabular}




\subsection{Five Dimensions of Illness Representation on Participants}

There are five dimensions of illness representation: identity, cause, timeline, consequences, and controllability. The description of the five dimensions of illness representation in patients with hypertension and diabetes was obtained through statistical descriptive analysis and categorization. Descriptive analysis was carried out using the SPSS 24.0 application, which showed the minimum, maximum, mean, and standard deviation values, then used to categorize the low, moderate, and high values of each of these dimensions in patients. The categorization process uses the formula in table 2 .

Table 2. The formula of categorization

\begin{tabular}{ll}
\multicolumn{1}{c}{ Formula } & Category \\
\hline $\mathrm{X} \geq(\mathrm{M}+\mathrm{SD})$ & High \\
\hline$(\mathrm{M}-\mathrm{SD})<\mathrm{X}<(\mathrm{M}+\mathrm{SD})$ & Moderate \\
\hline $\mathrm{X} \leq(\mathrm{M}-\mathrm{SD})$ & Low \\
\hline
\end{tabular}

The results for each dimension of illness representation show that dominant hypertension and diabetes patients are in the moderate category, meaning they have a sufficient understanding of each dimension of illness representation. In the dimension of Identity, it is seen that patients with hypertension (73.6\%) and diabetes $(63 \%)$ are dominant in the moderate category, in which patients are quite able to identify the symptoms of the disease they feel (identity). Furthermore, in the Cause dimension, it is also seen that patients with hypertension (68.1\%) and diabetes $(69.9 \%)$ are also dominant in the moderate category, in which patients are quite able to understand the cause of their disease. Table 3 also shows that patients with hypertension $(62.5 \%)$ and diabetes $(78.0 \%)$ are dominant in the moderate category on the Timeline dimension. This indicates that the patients have been quite able to understand the duration of their illness. Furthermore, on the Consequences dimension, it can be seen that both hypertensive $(65.3 \%)$ and diabetic $(68.5 \%)$ patients are in the moderate category, which is where they are considered to have quite understood the consequences of their disease. Finally, on the Controllability dimension, it is also seen that hypertensive patients $(63.9 \%)$ and diabetic patients $(71.2 \%)$ are dominant in the moderate category, which they should be able to understand and recognize the actions they can take to overcome their disease.

In addition, table 3 also shows that among the five dimensions of illness representation, the Identity dimension has the highest patient presentation, hypertensive patients with $73.6 \%$ in the moderate category. This shows that most hypertensive patients recognize and understand their symptoms when they suffer from the illness. On the other hand, the Controllability dimension shows the lowest patient presentation, diabetes patients in the low category of $9.6 \%$. This shows that diabetic patients on this dimension have not recognized and understood the extent to which their illness can be treated.

Table 3. Five dimensions of illness representation on participants

\begin{tabular}{|c|c|c|}
\hline \multirow[b]{2}{*}{ Dimension } & \multicolumn{2}{|c|}{ Category } \\
\hline & $\begin{array}{l}\text { Diabetes Melitus } \\
\text { N (\%) }\end{array}$ & $\begin{array}{c}\text { Hypertension } \\
\text { N (\%) }\end{array}$ \\
\hline \multirow{4}{*}{ Identity } & Std. Dev $=2.563$, Mean $=8.96$ & Std. Dev $=2.863$, Mean $=8.46$ \\
\hline & Low $=12(16.4 \%)$ & Low $=10(13.9 \%)$ \\
\hline & $\mathrm{Med}=46(63 \%)$ & $\operatorname{Med}=53(73.6 \%)$ \\
\hline & High $=16(20.5 \%)$ & High $=9(12.5 \%)$ \\
\hline \multirow{4}{*}{ Cause } & Std. Dev $=4.920$, Mean $=27.64$ & Std. Dev $=4.80$, Mean $=28.4$ \\
\hline & Low $=12(16.4 \%)$ & Low $=13(18.1 \%)$ \\
\hline & Med $=51(69.9 \%)$ & $\mathrm{Med}=49(68.1 \%)$ \\
\hline & High $=10(13.7 \%)$ & High $=10(13.8 \%)$ \\
\hline \multirow{4}{*}{ Timeline } & Std. Dev $=2.002$, Mean $=9.34$ & Std. Dev $=1.881$, Mean $=9.61$ \\
\hline & Low $=8(11 \%)$ & Low $=17(23.6 \%)$ \\
\hline & Med $=57(78 \%)$ & $\mathrm{Med}=45(62.5 \%)$ \\
\hline & High $=8(11 \%)$ & High $=10(13.9 \%)$ \\
\hline \multirow{4}{*}{ Consequences } & Std. Dev $=3.891$, Mean $=22.47$ & Std. Dev $=4.148$, Mean $=21.79$ \\
\hline & Low $=12(16.4 \%)$ & Low $=14(19.4 \%)$ \\
\hline & Med $=50(68.5 \%)$ & $\operatorname{Med}=47(65.3 \%)$ \\
\hline & High $=11(15.1 \%)$ & High $=11(15.3 \%)$ \\
\hline
\end{tabular}




\begin{tabular}{cc}
\hline Std. Dev $=2.461$, Mean $=21.51$ & Std. Dev $=2.984$, Mean $=21.65$ \\
Low $=14(19.2 \%)$ & Low $=20(27.8 \%)$ \\
Med $=52(71.2 \%)$ & Med $=46(63.9 \%)$ \\
High $=7(9.6 \%)$ & High $=26(27.8 \%)$ \\
\hline
\end{tabular}

\subsection{Description of the Dimensions of Illness Representation on the Demographics of Respondents}

\subsubsection{Description of Respondent Identity Dimension based on Demographics}

Table 4 shows that female and male hypertensive and diabetic patients have the same proportion in the moderate category. However, 27 respondents $(77.1 \%)$ with female hypertension patients and 23 respondents with diabetes $(71.9 \%)$ dominated the moderate category. This suggests that females understand the symptoms of their disease. Furthermore, in the age range of respondents, it can be seen that from all age ranges, patients seem to dominate in the moderate category. In the age range of 51-60 years, both hypertensive and diabetic patients with the age range of 51-60 years have been quite able to understand the symptom they feel.
In addition, the demographics of disease duration showed that of all disease duration ranges, the most significant proportion was in the moderate category. Hypertensive and diabetic patients dominate in the 15 year illness range, 39 (76.5\%) hypertensive patients and $24(63.2 \%)$ diabetic patients. This shows that both hypertensive and diabetic patients with an illness duration of 1-5 years have a sufficient understanding of the symptoms of their disease.

Last, on the type of treatment chosen by the respondent, it can be seen that of all types of treatment, the most significant proportion is in the moderate category. The dominant patients chose medical treatment and were in the moderate category, $18(66.7 \%)$ hypertension patients and $17(60.7 \%)$ diabetes patients. This means that hypertensive and diabetic patients who choose medical treatment have a sufficient understanding of the symptoms of their disease.

Table 4. Description of respondent identity dimension based on demographic

\begin{tabular}{|c|c|c|c|c|c|c|}
\hline \multirow{3}{*}{ Demographic } & \multicolumn{6}{|c|}{ Category } \\
\hline & \multicolumn{2}{|c|}{ Low } & \multicolumn{2}{|c|}{ Med } & \multicolumn{2}{|c|}{ High } \\
\hline & $\begin{array}{c}\text { Hypertension } \\
\text { N (\%) }\end{array}$ & $\begin{array}{c}\text { Diabetes } \\
\mathrm{N}(\%)\end{array}$ & $\begin{array}{c}\text { Hypertension } \\
\text { N (\%) }\end{array}$ & $\begin{array}{c}\text { Diabetes } \\
\mathrm{N}(\%)\end{array}$ & $\begin{array}{c}\text { Hypertension } \\
\text { N (\%) }\end{array}$ & $\begin{array}{c}\text { Diabetes } \\
\mathrm{N}(\%)\end{array}$ \\
\hline \multicolumn{7}{|l|}{ Sex } \\
\hline - Female & $2(5.7 \%)$ & $3(9.4 \%)$ & $27(77.1 \%)$ & $23(71.9 \%)$ & $6(17.2 \%)$ & $6(18.8 \%)$ \\
\hline - Male & $8(21.6 \%)$ & $9(22 \%)$ & $26(70.3 \%)$ & $23(36.1 \%)$ & $3(8.1 \%)$ & $9(22 \%)$ \\
\hline \multicolumn{7}{|l|}{ Age } \\
\hline$-<20-40$ & $1(7.1 \%)$ & 0 & $11(78.6 \%)$ & $6(85.7 \%)$ & $2(14.3 \%)$ & $1(14.3 \%)$ \\
\hline$-41-50$ & $2(14.3 \%)$ & $1(6.3 \%)$ & $9(64.3 \%)$ & $12(75 \%)$ & $3(21.4 \%)$ & $3(18.8 \%)$ \\
\hline$-51-60$ & $5(19.2 \%)$ & $6(24 \%)$ & $20(76.9 \%)$ & $14(56 \%)$ & $1(3.8 \%)$ & $5(20 \%)$ \\
\hline$-61-70$ & 0 & $4(23.5 \%)$ & $5(71.4 \%)$ & $9(52.9 \%)$ & $2(28.6 \%)$ & $4(23.3 \%)$ \\
\hline$->70$ & $2(18 / 2 \%)$ & $1(12.5 \%)$ & $8(72.7 \%)$ & $5(62.3 \%)$ & $1(9.1 \%)$ & $2(25 \%)$ \\
\hline \multicolumn{7}{|l|}{ Duration of Illness } \\
\hline$-1-5$ years & $7(13.7 \%)$ & $8(21.1 \%)$ & $39(76.5 \%)$ & $24(63.2 \%)$ & $5(9.8 \%)$ & $6(15.8 \%)$ \\
\hline$-6-10$ years & $1(16.7 \%)$ & $1(5.6 \%)$ & $12(80 \%)$ & $12(66.7 \%)$ & $2(13.3 \%)$ & $5(27.8 \%)$ \\
\hline$-11-20$ years & $2(33.3 \%)$ & $3(23.1 \%)$ & $2(33.3 \%)$ & $7(53.8 \%)$ & $2(33.3 \%)$ & $3(23.1 \%)$ \\
\hline$->20$ years & & 0 & & $3(75 \%)$ & & $1(25 \%)$ \\
\hline \multicolumn{7}{|l|}{ Treatment chosen } \\
\hline - Alternatives & 0 & $3(33.3 \%)$ & $7(10 \%)$ & $6(66.7 \%)$ & 0 & 0 \\
\hline - Medical & $6(22.2 \%)$ & $7(25 \%)$ & $18(66.7 \%)$ & $17(60.7 \%)$ & $3(11.1 \%)$ & $4(14.3 \%)$ \\
\hline - Buy medicine & $1(4.5 \%)$ & $2(11.1 \%)$ & $17(77.3 \%)$ & $11(61.1 \%)$ & $4(18.2 \%)$ & $5(27.8 \%)$ \\
\hline - Other & $1(16.7 \%)$ & 0 & $5(83.3 \%)$ & $8(61.5 \%)$ & 0 & $5(38.5 \%)$ \\
\hline - No Treatment & $2(20 \%)$ & 0 & $6(60 \%)$ & $4(80 \%)$ & $2(20 \%)$ & $1(20 \%)$ \\
\hline
\end{tabular}




\subsubsection{Description of Respondent Cause Dimension based on Demographics}

Table 5 shows that male hypertension and diabetic patients have the exact most significant proportion in the moderate category. Male patients have a more significant proportion than female patients, in patients with hypertension by $25(67.6 \%)$ respondents and in diabetic patients by $27(65.9 \%)$ respondents. This shows that male patients with hypertension and diabetes understand more about the causes of their disease than female patients. Furthermore, in the age range, it can be seen that the most significant proportion is in the moderate category of all periods. The age range of 51-60 years dominated the moderate category, 16 (61.5\%) hypertensive patients and $16(64 \%)$ diabetic patients. This shows that hypertensive and diabetic patients aged 51-60 years have a sufficient understanding of the causes of their disease. Then, in the duration of the disease suffered by the patient, it can be seen that the illness shows the most significant proportion in the moderate category from all timescales.

Hypertensive and diabetic patients with an illness duration of 1-5 years showed the most significant proportion in the moderate category, 32 (62.7\%) hypertensive patients and $26(68.4 \%)$ diabetic patients. This indicates that although the duration of the disease is still 1-5 years, they have quite understood the causes of their disease. Finally, it also seems to dominate in the moderate category for all types of treatment. However, hypertensive and diabetic patients preferred medical treatment in this category, $20(74.1 \%)$ hypertensive patients and 18 $(64.3 \%)$ diabetic patients.

\subsubsection{Description of Respondent Timeline Dimension based on Demographics}

Table 6 shows that male and female hypertensive and diabetic patients dominate the moderate category on this dimension. Male patients with hypertension and diabetes showed a more significant proportion than female patients in both illnesses, 25 (68\%) hypertension patients and 31 (75.6\%) diabetes patients. This means that male patients understand better the duration of their illness than female patients. Furthermore, from the five age ranges, it is seen that hypertension and diabetes patients dominate in the moderate category. Hypertensive and diabetic patients aged 51-60 showed the most significant proportion in the moderate category, 18 (69.2\%) hypertension patients and $19(76 \%)$ diabetes patients. This indicates that hypertensive and diabetic patients aged 51-60 years are assumed to have sufficient understanding regarding the duration of their disease. Then, the duration of the patient's illness was dominated by the moderate category. Patients with a disease duration of 1-5 years showed the most significant proportion in the moderate category, 30 $(58.8 \%)$ hypertension patients and 29 (76.3\%) diabetes patients. This indicates that hypertensive and diabetic patients with an illness duration of 1-5 years have a sufficient understanding of how long their illness will last. Finally, the type of treatment chosen by patients showed the most significant proportion in the moderate category for almost all types of treatment, but patients who chose medical treatment have a sufficient understanding of the duration of their illness.

Table 5. Description of respondent cause dimension based on demographic

\begin{tabular}{|c|c|c|c|c|c|c|}
\hline \multirow{3}{*}{ Demographic } & \multicolumn{6}{|c|}{ Category } \\
\hline & \multicolumn{2}{|c|}{ Low } & \multicolumn{2}{|c|}{ Med } & \multicolumn{2}{|c|}{ High } \\
\hline & $\begin{array}{l}\text { Hypertension } \\
\text { N (\%) }\end{array}$ & $\begin{array}{c}\text { Diabetes } \\
\mathrm{N}(\%)\end{array}$ & $\begin{array}{l}\text { Hypertension } \\
\text { N (\%) }\end{array}$ & $\begin{array}{c}\text { Diabetes } \\
\mathrm{N}(\%)\end{array}$ & $\begin{array}{l}\text { Hypertension } \\
\mathrm{N}(\%)\end{array}$ & $\begin{array}{c}\text { Diabetes } \\
\mathrm{N}(\%)\end{array}$ \\
\hline \multicolumn{7}{|l|}{ Sex } \\
\hline - Female & $7(20 \%)$ & $3(9.4 \%)$ & $22(62.9 \%)$ & $23(71.9 \%)$ & $6(17.1 \%)$ & $6(18.8 \%)$ \\
\hline - Male & $8(21.6 \%)$ & $9(22 \%)$ & $25(67.6 \%)$ & $27(65.9 \%)$ & $4(10.8 \%)$ & $5(12.2 \%)$ \\
\hline \multicolumn{7}{|l|}{ Age } \\
\hline$-<20-40$ & $5(35.7 \%)$ & 0 & $6(42.9 \%)$ & $6(85.7 \%)$ & $3(21.4 \%)$ & $1(14.3 \%)$ \\
\hline$-41-50$ & $2(14.3 \%)$ & $2(12.5 \%)$ & $9(64.3 \%)$ & $10(62.5 \%)$ & $3(21.4 \%)$ & $4(25 \%)$ \\
\hline$-51-60$ & $6(23.1 \%)$ & $6(24 \%)$ & $16(61.5 \%)$ & $16(61.5 \%)$ & $4(15.4 \%)$ & $3(12 \%)$ \\
\hline$-61-70$ & 0 & $4(23.5 \%)$ & $7(100 \%)$ & $7(100 \%)$ & 0 & $2(11.8 \%)$ \\
\hline$->70$ & $2(18.2 \%)$ & 0 & $9(81.8 \%)$ & $9(81.8 \%)$ & 0 & $1(12.5 \%)$ \\
\hline
\end{tabular}




\begin{tabular}{|c|c|c|c|c|c|c|}
\hline \multicolumn{7}{|l|}{ Duration of Illness } \\
\hline$-1-5$ years & $9(17.6 \%)$ & $7(18.4 \%)$ & $32(62.7 \%)$ & $26(68.4 \%)$ & $10(19.6 \%)$ & $5(13.2 \%)$ \\
\hline$-6-10$ years & $3(20 \%)$ & $1(5.6 \%)$ & $12(80 \%)$ & $14(77.8 \%)$ & 0 & $3(16.7 \%)$ \\
\hline$-11-20$ years & $2(33.3 \%)$ & $4(30.8 \%)$ & $4(66.7 \%)$ & $6(46.2 \%)$ & 0 & $3(23.1 \%)$ \\
\hline - > 20 years & & 0 & & $4(100 \%)$ & & \\
\hline \multicolumn{7}{|l|}{ Treatment chosen } \\
\hline - Alternatives & $1(14.3 \%)$ & $2(22.2 \%)$ & $5(71.4 \%)$ & $7(77.8 \%)$ & $1(14.3 \%)$ & 0 \\
\hline - Medical & $4(14.8 \%)$ & $6(21.4 \%)$ & $20(74.1 \%)$ & $18(64.3 \%)$ & $3(11.1 \%)$ & $4(14.3 \%)$ \\
\hline - Buy medicine & $7(31.8 \%)$ & $2(11.1 \%)$ & $11\left(56^{\wedge}\right)$ & $10(55.6 \%)$ & $4(18.2 \%)$ & $6(33.3 \%)$ \\
\hline - Other & 0 & $2(15.4 \%)$ & $5(83.3 \%)$ & $11(84.6 \%)$ & $1(16.7 \%)$ & 0 \\
\hline - No Treatment & $2(20 \%)$ & 0 & $7(70 \%)$ & $4(80 \%)$ & $1(10 \%)$ & $1(20 \%)$ \\
\hline
\end{tabular}

\subsubsection{Description of Respondent Consequences Dimension based on Demographics}

Similar to the previous dimensions, this dimension also shows that both male and female patients have the largest proportion in the moderate category. Female patients in the moderate category dominated patients with hypertension, 25 (71.4\%) hypertensive patients, while in diabetes, it was dominated by men in the moderate category, 26 (63.4\%) patients. This shows that female hypertensive patients and male diabetic patients have a sufficient understanding of the consequences of their disease. Then, patients with all age ranges showed the most significant proportion in the moderate category. However, patients aged 51-60 years dominated the moderate category, $16(61.5 \%)$ hypertensive patients and $14(56 \%)$ diabetic patients. This indicates that patients aged 51-60 years are quite aware of the consequences of their disease. Furthermore, the duration of the illness in patients with hypertension and diabetes showed the most significant proportion in the moderate category. Patients with a disease duration range of 1-5 years dominated this category, $34(66.7 \%)$ hypertensive patients and $27(71.1 \%)$ diabetic patients. This indicates that patients with a disease duration of 1-5 years have a sufficient understanding of the consequences of their illness. Finally, all types of treatment also showed the largest proportion in the moderate category. However, patients who chose medical treatment again dominated the moderate category, as many as $17(63 \%)$ hypertensive patients and $22(78.6 \%)$ diabetic patients. This means that patients on medical treatment understand well the consequences of their illness.

\subsubsection{Description of Respondent Controllability Dimension based on Demographics}

The last dimension, the Controllability dimension, shows that both female and male patients dominate the moderate category for this dimension. However, it was seen that male patients had a more significant proportion than female patients, 23 (62.2\%) hypertension patients and $30(73.2 \%)$ diabetes patients. This shows that male hypertensive and diabetic patients have a sufficient understanding of the extent to which they can control or treat their disease. Furthermore, each patient's age range shows the largest proportion in the moderate category. Similar to the previous dimensions, this dimension also shows that patients aged 51-60 years dominated the moderate category, with $18(69.2 \%)$ hypertensive patients aged 51-60 years having sufficient understanding regarding the extent to which their disease can be treated. Then, for the duration of the patient's illness in all duration ranges, the largest proportion was in the moderate category. Patients with an illness duration of 1-5 years showed the largest proportion, namely $33(64.7 \%)$ hypertensive patients and $29(76.3 \%)$ diabetic patients. This shows that patients with an illness duration of 1-5 years have a sufficient understanding of controlling their disease. Finally, patients' treatment types also showed the largest proportion in the moderate category. Patients who chose the type of medical treatment dominated the moderate category on this dimension, $17(63 \%)$ hypertensive patients and 19 (67.9\%) diabetic patients. This means that patients who choose this type of medical treatment have a sufficient understanding of the extent to which they can cope with their illness. Patients aged 51-60 years have sufficient understanding regarding the extent to which their disease can be treated. Then, for the duration of the patient's illness in all duration ranges, 
the largest proportion was in the moderate category. Patients with an illness duration of 1-5 years showed the largest proportion, namely 33 (64.7\%) hypertensive patients and $29(76.3 \%)$ diabetic patients. This shows that patients with an illness duration of 1-5 years have a sufficient understanding of controlling their disease. Finally, patients' treatment types also showed the largest proportion in the moderate category. Patients who chose the type of medical treatment dominated the moderate category on this dimension, 17 (63\%) hypertensive patients and $19(67.9 \%)$ diabetic patients. This means that patients who choose this type of medical treatment have a sufficient understanding of the extent to which they can cope with their illness.

Table 6. Description of respondent timeline dimension based on demographic

\begin{tabular}{|c|c|c|c|c|c|c|}
\hline \multirow{3}{*}{ Demographic } & \multicolumn{6}{|c|}{ Category } \\
\hline & \multicolumn{2}{|c|}{ Low } & \multicolumn{2}{|c|}{ Med } & \multicolumn{2}{|c|}{ High } \\
\hline & $\begin{array}{c}\text { Hypertension } \\
\mathrm{N}(\%)\end{array}$ & $\begin{array}{c}\text { Diabetes } \\
N(\%)\end{array}$ & $\begin{array}{c}\text { Hypertension } \\
\mathrm{N}(\%)\end{array}$ & $\begin{array}{c}\text { Diabetes } \\
\mathrm{N}(\%)\end{array}$ & $\begin{array}{c}\text { Hypertension } \\
\mathrm{N}(\%)\end{array}$ & $\begin{array}{c}\text { Diabetes } \\
\mathrm{N}(\%)\end{array}$ \\
\hline \multicolumn{7}{|l|}{ Sex } \\
\hline - Female & $11(31 \%)$ & $2(6.3 \%)$ & $18(51 \% 0$ & $26(81.3 \%)$ & $6(17 \%)$ & $4(12.5 \%)$ \\
\hline - Male & $8(22 \%)$ & $6(14.6 \%)$ & $25(68 \%)$ & $31(75.6 \%)$ & $4(11 \%)$ & $4(9.8 \%)$ \\
\hline \multicolumn{7}{|l|}{ Age } \\
\hline$-<20-40$ & $7(50 \%)$ & $1(14.3 \%)$ & $6(42.9 \%)$ & $6(85.7 \%)$ & $1(7.1 \%)$ & 0 \\
\hline$-41-50$ & $6(42.9 \%)$ & $3(18.8 \%)$ & $6(47.9 \%)$ & $11(68.8 \%)$ & $2(14.3 \%)$ & $2(12.5 \% 0$ \\
\hline$-51-60$ & $4(15.4 \%)$ & $3(12 \%)$ & $18(69.2 \%)$ & $19(76 \%)$ & $4(15.4 \%)$ & $3(12 \%)$ \\
\hline$-61-70$ & $1(14.3 \%)$ & 0 & $4(57.1 \%)$ & $15(88.2 \%)$ & $2(28.6 \%)$ & $2(11.8 \%)$ \\
\hline$->70$ & $1(9.1 \%)$ & $1(12.5 \%)$ & $9(81.8 \%)$ & $6(75 \%)$ & $1(9.1 \%)$ & $1(12.5 \%)$ \\
\hline \multicolumn{7}{|l|}{ Duration of Illness } \\
\hline$-1-5$ years & $17(33.3 \%)$ & $5(13.2 \%)$ & $30(58.8 \%)$ & $29(76.3 \%)$ & $4(7.8 \%)$ & $4(10.5 \%)$ \\
\hline$-6-10$ years & $2(13.3 \%)$ & $2(11.1 \%)$ & $8(53.3 \%)$ & $14(77.8 \%)$ & $5(33.3 \%)$ & $2(11.1 \%)$ \\
\hline$-11-20$ years & 0 & 0 & $5(83.3 \%)$ & $10(76.9 \%)$ & $1(16.7 \%)$ & $3(23.1 \%)$ \\
\hline - > 20 years & 0 & $1(25 \%)$ & 0 & $3(75 \%)$ & 0 & 0 \\
\hline \multicolumn{7}{|l|}{ Treatment chosen } \\
\hline - Alternatives & $4(57.1 \%)$ & $2(22.2 \%)$ & $2(28.6 \%)$ & $6(66.7 \%)$ & $1(14.3 \%)$ & $1(11.1 \%)$ \\
\hline - Medical & $8(29.6 \%)$ & $3(10.7 \%)$ & $15(55.6 \%)$ & $21(75 \%)$ & $4(14.8 \%)$ & $4(14.3 \%)$ \\
\hline - Buy medicine & $4(18.2 \%)$ & $2(11.1 \%)$ & $15(68.2 \&)$ & $14(77.8 \%)$ & $3(13.6 \%)$ & $2(11.1 \%)$ \\
\hline - Other & $1(16.7 \%)$ & $1(7.7 \%)$ & $5(83.3 \%)$ & $12(92.3 \%)$ & 0 & 0 \\
\hline - No Treatment & $2(20 \%)$ & 0 & $6(60 \%)$ & $4(80 \%)$ & $2(20 \%)$ & $1(20 \%)$ \\
\hline
\end{tabular}

Table 7. Description of respondent consequences dimension based on demographic

\begin{tabular}{|c|c|c|c|c|c|c|}
\hline \multirow{3}{*}{ Demographic } & \multicolumn{6}{|c|}{ Category } \\
\hline & \multicolumn{2}{|c|}{ Low } & \multicolumn{2}{|c|}{ Med } & \multicolumn{2}{|c|}{ High } \\
\hline & $\begin{array}{c}\text { Hypertension } \\
\mathrm{N}(\%)\end{array}$ & $\begin{array}{c}\text { Diabetes } \\
\mathrm{N}(\%)\end{array}$ & $\begin{array}{c}\text { Hypertension } \\
\mathrm{N}(\%)\end{array}$ & $\begin{array}{c}\text { Diabetes } \\
\mathrm{N}(\%)\end{array}$ & $\begin{array}{c}\text { Hypertension } \\
\mathrm{N}(\%)\end{array}$ & $\begin{array}{c}\text { Diabetes } \\
\mathrm{N}(\%)\end{array}$ \\
\hline \multicolumn{7}{|l|}{ Sex } \\
\hline - Female & $6(17.1 \%)$ & $3(9.4 \%)$ & $25(71.4 \%)$ & $24(75 \%)$ & $4(11.4 \%)$ & $5(15.6 \%)$ \\
\hline - Male & $8(21.6 \%)$ & $9(22 \%)$ & $22(59.5 \%)$ & $26(63.4 \%)$ & $7(18.9 \%)$ & $6(14.6 \%)$ \\
\hline \multicolumn{7}{|l|}{ Age } \\
\hline$-<20-40$ & $4(28.6 \%)$ & $1(14.3 \%)$ & $10(71.4 \%)$ & $5(71.4 \%)$ & 0 & $1(14.3 \%)$ \\
\hline$-41-50$ & $1(7.1 \%)$ & $4(25 \%)$ & $12(85.7 \%)$ & $9(56.3 \%)$ & $1(7.1 \%)$ & $3(18.8 \%)$ \\
\hline$-51-60$ & $3(11.5 \%)$ & $6(24 \%)$ & $16(61.5 \%)$ & $14(5650$ & $7(26.9 \%)$ & $5(20 \%)$ \\
\hline$-61-70$ & $2(28.6 \%)$ & $1(5.6 \%)$ & $3(42.9 \%)$ & $14(82.4 \%)$ & $2(28.6 \%)$ & $2(11.8 \%)$ \\
\hline$->70$ & $2(18.2 \%)$ & 0 & $9(81.8 \%)$ & $8(100 \%)$ & $1(9.1 \%)$ & 0 \\
\hline
\end{tabular}




\begin{tabular}{|c|c|c|c|c|c|c|}
\hline \multicolumn{7}{|l|}{ Duration of Illness } \\
\hline$-1-5$ years & $10(19.6 \%)$ & $6(15.8 \%)$ & $34(66.7 \%)$ & $27(71.1 \%)$ & $7(13.7 \%)$ & $5(13.2 \%)$ \\
\hline$-6-10$ years & $3(20 \%)$ & $4(22.2 \%)$ & $8(53.3 \%)$ & $11(61.7 \%)$ & $4(26.7 \%)$ & $3(16.7 \%)$ \\
\hline - $11-20$ years & $1(16.7 \%)$ & $2(15.4 \%)$ & $5(83.3 \%)$ & $8(61.5 \%)$ & 0 & $3(23.1 \%)$ \\
\hline - > 20 years & 0 & 0 & 0 & $4(100 \%)$ & 0 & 0 \\
\hline \multicolumn{7}{|l|}{ Treatment chosen } \\
\hline - Alternatives & $1(14.3 \%)$ & $1(11.1 \%)$ & $6(85.7 \%)$ & $6(66.7 \%)$ & 0 & $2(22.2 \%)$ \\
\hline - Medical & $5(18.5 \%)$ & $2(7.1 \%)$ & $17(63 \%)$ & $22(78.6 \%)$ & $5(18.5 \%)$ & $4(14.3 \%)$ \\
\hline - Buy medicine & $5(22.7 \%)$ & $5(27.8 \%)$ & $15(68.2 \%)$ & $11(61.1 \%)$ & $2(9.1 \%)$ & $2(11.1 \%)$ \\
\hline - Other & $1(16.7 \%)$ & $3(23.1 \%)$ & $4(66.7 \%)$ & $8(61.5 \%)$ & $1(10.7 \%)$ & $2(15.4 \%)$ \\
\hline - No Treatment & $1(10 \%)$ & $1(20 \%)$ & $5(50 \%)$ & $3(60 \%)$ & $4(40 \%)$ & $1(20 \%)$ \\
\hline
\end{tabular}

Table 8. Description of respondent controllability dimension based on demographic

\begin{tabular}{|c|c|c|c|c|c|c|}
\hline \multirow{3}{*}{ Demographic } & \multicolumn{6}{|c|}{ Category } \\
\hline & \multicolumn{2}{|c|}{ Low } & \multicolumn{2}{|c|}{ Med } & \multicolumn{2}{|c|}{ High } \\
\hline & $\begin{array}{l}\text { Hypertension } \\
\text { N (\%) }\end{array}$ & $\begin{array}{l}\text { Diabetes } \\
\mathrm{N}(\%)\end{array}$ & $\begin{array}{c}\text { Hypertension } \\
\text { N }(\%)\end{array}$ & $\begin{array}{l}\text { Diabetes } \\
\mathrm{N}(\%)\end{array}$ & $\begin{array}{c}\text { Hypertension } \\
\text { N (\%) }\end{array}$ & $\begin{array}{c}\text { Diabetes } \\
\mathbf{N}(\%)\end{array}$ \\
\hline \multicolumn{7}{|l|}{ Sex } \\
\hline - Female & $10(28.6 \%)$ & $5(28.1 \%)$ & $23(65.7 \%)$ & $21(65.6 \%)$ & $2(5.7 \%)$ & $2(6.3 \%)$ \\
\hline - Male & $10(27 \%)$ & $9(12.2 \%)$ & $23(62.2 \%)$ & $30(73.2 \%)$ & $4(10.8 \%)$ & $6(14.6 \%)$ \\
\hline \multicolumn{7}{|l|}{ Age } \\
\hline$-<20-40$ & $6(42.9 \%)$ & $2(28.6 \%)$ & $6(42.9 \%)$ & $4(57.1 \%)$ & $2(14.3 \%)$ & $1(14.3 \%)$ \\
\hline$-41-50$ & $5(35.7 \%)$ & $4(25 \%)$ & $8(57.1 \%)$ & $10(62.5 \%)$ & $1(7.1 \%)$ & $2(12.5 \%)$ \\
\hline$-51-60$ & $6(23.1 \%)$ & $3(12 \%)$ & $18(69.2 \%)$ & $21(84 \%)$ & $2(7.7 \%)$ & $1(4 \%)$ \\
\hline$-61-70$ & 0 & $2(11.8 \%)$ & $7(100 \%)$ & $11(64.7 \%)$ & 0 & $4(23.5 \%)$ \\
\hline$->70$ & $3(27.3 \%)$ & $3(37.5 \%)$ & $8(72.7 \%)$ & $5(62.5 \%)$ & 0 & 0 \\
\hline \multicolumn{7}{|l|}{ Duration of Illness } \\
\hline$-1-5$ years & $14(27.5 \%)$ & $5(13.2 \%)$ & $33(64.7 \%)$ & $29(76.3 \%)$ & $4(7.8 \%)$ & $4(10.5 \%)$ \\
\hline$-6-10$ years & $4(26.7 \%)$ & $6(33.3 \%)$ & $10(66.7 \%)$ & $10(55.6 \%)$ & $1(6.7 \%)$ & $2(11.1 \%)$ \\
\hline$-11-20$ years & $2(33.3 \%)$ & $2(15.4 \%)$ & $3(50 \%)$ & $9(69.2 \%)$ & $1(16.7 \%)$ & $2(15.4 \%)$ \\
\hline$->20$ years & 0 & $1(25 \%)$ & 0 & $3(75 \%)$ & 0 & 0 \\
\hline \multicolumn{7}{|l|}{ Treatment chosen } \\
\hline - Alternatives & $2(28.6 \%)$ & $2(22.2 \%)$ & $5(71.4 \%)$ & $6(66.7 \%)$ & 0 & $1(11.1 \%)$ \\
\hline - Medical & $8(29.6 \%)$ & $6(21.4 \%)$ & $17(63 \%)$ & $19(67.9 \%)$ & $2(7.4 \%)$ & $3(10.7 \%)$ \\
\hline - Buy medicine & $6(27.3 \%)$ & $3(16.7 \%)$ & $14(63.6 \%)$ & $13(72.2 \%)$ & $2(9.1 \%)$ & $2(11.1 \%)$ \\
\hline - Other & $1(16.7 \%)$ & $3(23.1 \%)$ & $5(83.3 \%)$ & $9(69.2 \%)$ & 0 & $1(7.7 \%)$ \\
\hline - No Treatment & $3(30 \%)$ & 0 & $5(50 \%)$ & $4(80 \%)$ & $2(20 \%)$ & $1(20 \%)$ \\
\hline
\end{tabular}




\subsection{Hypothesis Test Results on each Dimension of Illness Representation}

Hypothesis testing was carried out by independent non-parametric t-test analysis, namely the MannWhitney test. This test was conducted to see differences in illness representation in hypertensive and diabetic patients. The Mann-Whitney test was carried out per-dimensional illness representation: identity, causes, timeline, consequences, and controllability on two groups of respondents.

Table 9 shows the value of the results of data analysis using the Mann Whitney test, which can be seen from the Asymp value. Sig. (2-tailed) each dimension of illness representation. The dimensions of identity, causes, timeline, consequences, and controllability show the Asymp value. Sig. (2-tailed) were $0.364,0.373,0.642,0.291$, and 0.742 , respectively. These values are greater than the probability value of 0.05 . This means that $\mathrm{H}_{0}$, which says that there is a difference between hypertensive and diabetic patients is rejected. Thus, it can be said that there is no difference between hypertensive and diabetic patients on all dimensions of illness representation.

Table 9. Values of Mann-Whitney test on illness representation dimensions

\begin{tabular}{cccccc} 
Values of Mann & \multicolumn{5}{c}{ Dimensions } \\
\cline { 2 - 6 } Whitney Test & Identity & Causes & Timeline & Consequences & Controllability \\
\hline Mann Whitney U & 2400.50 & 2403.50 & 2512.50 & 2362.000 & 2546.00 \\
\hline Wilcoxon W & 5028.50 & 5104.50 & 5213.50 & 4990.000 & 5247.00 \\
\hline Z & -.908 & -.890 & -.465 & -1.05 & -.329 \\
\hline $\begin{array}{c}\text { Asymp. Sig. } \\
\text { (2-tailed) }\end{array}$ & .364 & .323 & .642 & .291 & .742 \\
\hline
\end{tabular}

\section{DISCUSSION}

The first dimension of illness representation, identity, shows no difference in respondents with hypertension and diabetes. This means that the hypertensive and diabetic patients who were respondents in this study had no difference in recognizing the symptoms or symptoms of their disease. This is related to how respondents feel the symptoms or symptoms they experience and then label them. Demographic data shows that both hypertensive and diabetic respondents can recognize the symptoms they are experiencing. This can also be seen from the results of hypothesis testing, which indicates that there is no difference in respondents with diabetes and hypertension in recognizing the symptoms of their disease.

Infodatin Hypertension [14] suggests that hypertension is characterized by an increase in systolic blood pressure of more than $140 \mathrm{mmHg}$ and systolic blood pressure of more than $90 \mathrm{mmHg}$ on two measurements with an interval of five minutes in a state of sufficient rest or calm. Meanwhile, diabetes is characterized by an increase in glucose concentration in the blood [15]. However, study respondents tend to recognize their symptoms better based on what they feel in their bodies.
Based on the results of interviews and questionnaires, it was found that respondents with hypertension and diabetes tend to experience the same initial symptoms, such as headaches, dizziness, fatigue, and loss of strength or energy. Hypertensive respondents also admitted that they tend to recognize when their blood pressure rises, namely from headaches or neck tension. Meanwhile, the diabetic respondents also often feel aware of their condition when they feel tired, have headaches, or have trouble sleeping. This shows that respondents from these two

diseases tend to have the same perception regarding their symptoms.

The absence of differences in diabetic and hypertensive respondents in recognizing their disease could also be due to the lack of specific symptoms in hypertensive patients. This is supported by the opinion of Brewer et al. (2002), which suggests that hypertension is a chronic condition that does not have apparent symptoms but requires long-term treatment [16].

Furthermore, the second dimension of illness representation, causes, also shows no difference in respondents with hypertension and diabetes. This dimension relates to how individuals recognize or perceive the cause of their illness. This means that 
both respondents with hypertension and diabetes do not have differences in recognizing and perceiving the causes of their disease.

Infodatin (Ministry of Health RI, 2014) suggests risk factors for hypertension, such as age, gender, family history, genetics, smoking habits, salt consumption, consumption of saturated fat, use of used cooking oil, alcohol consumption habits, obesity, stress, lack of physical activity, and use of estrogen. Meanwhile, the risk factors for diabetes, namely: race and ethnicity, age, gender, family history, history of giving birth to a baby weighing more than 4000 grams, history of birth with low weight (less than 2500 grams), obesity, lack of physical activity, dyslipidemia, hypertension, and unhealthy/balanced diet [2]. This shows that these two diseases have the same risk or cause.

Based on the results of interviews and questionnaires conducted to respondents, it was found that both hypertensive and diabetic respondents tended to reveal the cause of their illness due to themselves (in this case, an unhealthy lifestyle, factors of food consumed, and other reasons), stress factors, and historical factors. The absence of differences in respondents with diabetes and hypertension in recognizing the cause of their disease indicates the close relationship between hypertension and diabetes.

The third dimension of illness representation is the timeline. This dimension relates to the individual's perception or belief regarding the duration of the illness. The results of hypothesis testing indicate that there is no difference between respondents with hypertension and diabetes on this dimension. This means that respondents with hypertension and respondents with diabetes have no difference in perceiving and recognizing the duration of their illness.

The demographics of respondents show that respondents with hypertension and diabetes show the most significant proportions in the duration of the illness 1 to 5 years. In addition, the dimensions of the timeline from respondents with hypertension and diabetes also show that the dominant respondents recognize and perceive the duration of their illness. Research conducted by Broadbent et al. (2006) shows that the duration of the disease has an association with illness representation because the longer the individual experiences the disease, the more aware the individual is about the threat of disease and how to overcome it [17]. The results of interviews and questionnaires also show that respondents with hypertension and diabetes mostly perceive their disease to last for a long time.

The fourth dimension of illness representation is consequences. This relates to how individuals recognize or represent the consequences of their illness. Based on the results of hypothesis testing, it was found that there was no difference between diabetes and hypertension respondents on the dimensions of consequences. This means that there is no difference in respondents with diabetes and hypertension representing the consequences of the disease they are experiencing. Based on the results of interviews and questionnaires, it was found that respondents with hypertension and diabetes tend to perceive their disease as having significant consequences and affecting their lives. In addition, respondents also considered their illness to be serious.

Finally, the dimension of controllability on illness representation. This dimension looks at how individuals represent their disease and the extent to which the disease can be treated or controlled. The hypothesis test results showed that there was no difference between diabetes and hypertension respondents on this dimension. This means that both hypertensive and diabetic respondents have no difference in perceiving and recognizing the extent to which their disease can be treated.

Infodatin [2] shows that both hypertension and diabetes need to be overcome or treated by taking drugs, regular check-ups to doctors or health centers, and lifestyle modifications (such as: regulating diet, not smoking, and so on). Ross (2004) suggests that perceived controllable or treatable disease is associated with problem-focused coping compared with untreatable disease or chronic disease that tends to produce maladaptive responses (such as rejection) [18]. The results of interviews and questionnaires given to respondents with hypertension and diabetes show that most respondents perceive that their disease will improve over time and that many things can be done to control their symptoms.

In addition, there are several other findings in this study. First, hypertensive patients who choose alternative medicine are known to be quite able to recognize their symptoms. If patients can recognize the symptoms they are experiencing, they should seek medical attention for proper diagnosis and treatment. Based on the interviews conducted by researchers with one of the internal medicine specialists, he 
stated that many factors influence the understanding of hypertension and diabetes patients regarding their diseases, such as education level, age, length of illness, social and culture. Sometimes, patients with hypertension and diabetes in Makassar City also often think they understand very well about their disease, even though it is only a layman's understanding. He added that patients should go to a doctor and get drugs with clearly measurable and compositional compositions, unlike alternative treatments, which are not measurable.

The second finding of this study is that hypertensive patients who choose alternative medicine still lack an understanding of the duration of their illness. This is in line with the opinion of internal medicine specialists who say that, in general, hypertensive and diabetic patients who are newly affected by the illness still do not understand their illness. In addition, he also added that most patients with hypertension and diabetes do not know that the illness they are experiencing will suffer for a lifetime because it is a chronic and degenerative disease, so they will experience complications and have to take medication for life.

Overall, it can be seen that there is no difference between respondents with hypertension and respondents with diabetes in their perception of their illness. This could be because hypertension and diabetes are similar diseases. Balogun and Salako (2011) suggested that hypertension and diabetes are two diseases that often appear together in an individual [19]. Previous studies have also suggested that hypertension and diabetes are related or related to illnesses. For example, research conducted by Movahed et al. (2010) showed an association between hypertension and diabetes in the population in the United States [20]. In addition, Oli et al. (1981), Oyewo et al. (1989), and Agaba et al. (2002) also showed an association between hypertension and diabetes [21-23].

Hypertension and diabetes are two diseases that patients often suffer simultaneously or at close intervals. Research conducted by Silih et al. (2012) showed a significant relationship between diabetes mellitus and hypertension [23]. In addition, this study is also supported by other studies by Mubarak et al. (2008) and Teo et al. (2011), which show that there is a relatively high prevalence of hypertension in people with diabetes mellitus [25,26]. Internal medicine specialists also stated that hypertension and diabetes are two related diseases. This can be a factor in the absence of differences in illness representation in respondents with hypertension and diabetes because the representation of the two diseases is similar.

\section{AUTHORS' CONTRIBUTIONS}

Annisa Yurna designed the study, looked for the respondents, analyzed the data, wrote the manuscript, reviewed the data analysis, and approved the final version of the manuscript. Grestin Sandy and Mayenrisari Arifin helped design the study, reviewed the statistical analysis, reviewed the data analysis, and helped to conduct the study. All the authors read and approved the final version of the manuscript.

\section{ACKNOWLEDGMENT}

We thank all of the respondents who are still willing to provide information as research data even though they are sick. We thank Dr. Muhammad Tamar, M.Psi, Nirwana Permatasari, M.Psi., Psikolog, Istiana Tadjuddin., M.Psi., Psikolog, and Juwita Amal, M.Psi., Psikolog for their guidance and feedbacks for this research. We thank the health research ethics committee of the Faculty of Medicine, Hasanuddin University, which has issued an ethical license for this research. This study was supported by the Psychology Department, Faculty of Medicine, Hasanuddin University.

\section{REFERENCES}

[1] Young, J. T. Illness Behavior: a selective review and synthesis/. Sociology of health \& illness. (2004). 26 (01): 1-31

[2] Kementerian Kesehatan RI. Data dan Informasi Profil Kesehatan Indonesia. (2018).

[3] Kementrian Kesehatan RI. Riskesdas. (2018).

[4] Leventhal, H., Meyer, D., and Nerenz, D. The Common Sense Representation of Illness Danger. Medical Psychology. (1980). 2: 7-30.

[5] Velea, O. Popa. Human Behavioral Sciences. Application in Medicine. (2010).

[6] Ogden, J. Health Psychology. Fifth Edition. USA: Mc-Graw Hill. (2012).

[7] Lau, R. R., dan Hartman, K. A. Common Sense Representations of Common Illnesses. Health Psychology. (1983). 2(2), 167-185.

[8] Kemp, S. The Role of Illness Representations in the Process of Coping and Psychological Adjustment among Adults with Epilepsy. 
(Thesis). School of Medicine: The University of Leeds. (1996).

[9] Singh, R. Psychological Model of Illness. Newcastle: Cambridge Scholars Publishing. (2011).

[10] Leventhal, H., Leventhal, E. A., dan Cameron, L. in Baum, A., Revenson, T. A., dan Singer, J. E. Handbook of Health Psychology. London: Lawrence Erlbaum Associates Publishers. (2001).

[11] Leventhal, H., Leventhal, E. A., \& Contrada, R. J. Self-regulation, Health, and Behavior: A Perceptual-cognitive Approach. Psychology \& Health. (1998). 13, 717-733.

[12] Diefenbach, M. A dan Leventhal, H. The Common-sense Model of Illness Representation: Theoretical and Practical Considerations. Journal of Social Distress and the Homeless. (1996). 5(1).

[13] Weinman, J., Petrie, K. J., Moss-morris, \& Horne, R. The Illness Perception Questionnaire: A New Method for Assessing the Cognitive Representation of Illness. Psychology and Health. (1996). 11, pp. 43-105.

[14] Kementerian Kesehatan RI. Pusat Data dan Informasi Kementerian Kesehatan RI: Hipertensi. (2014).

[15] Kementerian Kesehatan RI. Pusat Data dan Informasi Profil Kementerian Kesehatan RI: Diabetes. (2014).

[16] Brewer, N.T., Chapman, G. B., Brownlee, S., dan Leventhal, E. A. Cholesterol Control, Medication Adherence, and Illness Cognition. British Journal of Health Psychology. (2002). 7(4), 433-447.

[17] Broadbent E, Petrie K, Main J, Weinman J. The Brief Illness Perception Questionnaire. J Psychosom Res. (2006). 60: 631-637.

[18] Ross, S., Walker, A., dan MacLeod, M.J. Patient Compliance in Hypertension: Role of Illness Perceptions and Treatment Beliefs. Journal of Human Hypertension. (2004). 18, 607-613.

[19] Balogun, W. O., dan Salako, B. L. CoOccurrence of Diabetes and Hypertension: Pattern and Factors with Order of Diagnosis among Nigerians. Annals of Ibadan Postgraduate Medicine. (2011). 9 (2).

[20] Movahed MR., Sattur S., dan Hashemzadeh M.
Independent association between type 2 diabetes mellitus and hypertension over a period of 10 years in a large inpatient population. Clin Exp Hypertens. (2010). 32(3):198-201.

[21] Oli JM., dan Ikeh, V.O. Diabetic Mellitus and hypertension in an African population. J R Coll Physicians London. (1981). 20, 32-35.

[22] Oyewo E. A, Ajayi, A. A. dan Ladipo, G.O.A. A therapeutic audit in the management of hypertension in Nigerians. East Afr Med J. (1989). 66, 458- 467.

[23] Agaba I. E., Anteyi E. A., Puepet F. H., Omudu P. A., dan Idoko J. A. Hypertension in type 2 diabetes in Jos Teaching Hospital, Jos Nigeria. Highland Medical Research Journal. (2002). 1(2), 22- 24.

[24] Silih, Y., Hasibuan, P., dan Novianry, V. Hubungan Antara Diabetes Melitus dengan Kejadian Hipertensi di Kecamatan Pontianak Selatan. Naskah Publikasi. Universitas Tanjungpura: Fakultas Kedokteran. (2012).

[25] Mubarak, F. M., Froelicher, E. S, Jaddou, H. Y, Ajlouni, K. M. Hypertension among 1000 patients with type 2 diabetes attending a national diabetes center in Jordan. Ann Saudi Med. (2008). 28:346.

[26] Teo, C., Chung, W., Khaw, C., Rashid, A. Hypertension and Diabetes Mellitus Among The Residents of An Old Folks Home in North Malaysia. The Internet Journal of Geriatrics and Gerontology. (2011). 6: 1-3. 